\title{
Correction to: A systematic review of the literature describing the outcomes of near- peer mentoring programs for first year medical students
}

Olawunmi Akinla ${ }^{1,2^{*}}$, Pamela Hagan ${ }^{2}$ and William Atiomo ${ }^{3}$

\section{Correction}

Following publication of the original article [1], the author reported incorrect referencing in Table 1 as the references of the papers in the table don't match with the text.

The correct referencing for Table 1 is as folows:

Abdolalizadeh 25

Singh 23

Yusoff 24

McLean 22

Kososko-Lasiki 21

\section{Author details}

${ }^{1}$ Macclesfield District General Hospital, Macclesfield, UK. ${ }^{2}$ School of Medicine, The University of Nottingham, Nottingham, UK. ${ }^{3}$ School of Medicine, Queens Medical Centre, The University of Nottingham, Derby Road, Nottingham NG7 2UH, UK.

Published online: 13 July 2018

\section{Reference}

1. Akinla $\mathrm{O}$, et al. A systematic review of the literature describing the

outcomes of near-peer mentoring programs for first year medical students.

BMC Med Educ. 2018;18:98. https://doi.org/10.1186/s12909-018-1195-1.

\footnotetext{
*Correspondence: olawunmiakinla@gmail.com

${ }^{1}$ Macclesfield District General Hospital, Macclesfield, UK

${ }^{2}$ School of Medicine, The University of Nottingham, Nottingham, UK

Full list of author information is available at the end of the article
} 